\title{
YẾU TỐ LIÊN QUAN ĐẾN KIẾN THỨC, THƯCC HÀNH VỀ PHÒNG VÀ PHÁT HIẾN SỚM UNG THƯ VÚ Ở PHU NỮ 18-60 TUỔI TẠI THÀNH PHỐ CẦN THO' NĂM 2020
}

\section{TÓM TẮT}

Đă̆t vấn đê: nhằm tăng cường kiến thức, thực hành phòng và phát hiện sớm ung thư vú (UTV) cho phụ nữ 18-60 tuổi, việc tìm hiểu yếu tố ảnh hưởng có ý nghĩa quan trọng trong xác định các nội dung cần can thiêp. Mục tiêu: Xác định một số yếu tố liên quan đển kiến thức, thực hành tốt về phòng và phát hiện sớm UTV ở phụ nử 18-60 tuổi tại thành phố Cần Thơ. Đối tượng và phương pháp nghiên cứu: Nghiên cứu mô tả cắt ngang 286 phụ nữ 18-60 tuổi tại thành phố Cần Thơ từ tháng 5 đển tháng 9 năm 2020. Phân tích hồi quy logistic để xác định yểu tố liên quan đến kiến thức, thực hành về phòng và phát hiên sớm UTV. Xử lý số liệu bằng phần mềm SPSS 20.0. Kết quả: nghiên cứu ghi nhận 3 yếu tố liên quan đến kiến thức, trong đó, nhóm phụ nữ sống thành thị, trình độ trên trung hoc cơ sở (THCS), có tìm hiêuu thông tin về UTV có kiến thức tốt hơn nhóm ở nông thôn 1,944 lần (KTC95\% 1,015-3,722), học vấn từ THCS trở xuống 2,856 lần (KTC95\% 1,169-6,979) và không tìm hiểu thông tin về UTV 3,264 lần (KTC95\% $1,728-6,163)$ với $p<0,05$. Yếu tố quan đến thực hành gồm tiền sử gia đình có bệnh UTV, có tìm hiếu thông tin về UTV và kiến thức tốt về sàng lọc, phát hiện UTV; sự khác biệt có ý nghĩa thống kê với $p<0,05$ và OR tương ứng là 4,106 (KTC95\% 1,404-12,01); 2,763 (KTC95\% 1,298-5,882) và 2,089 (KTC95\% 1,01-4,32). Kết luận: Can thiệp vào các yếu tố ảnh hưởng đên kiến thức, thực hành về phòng và phát hiên sớm UTV ở phụ nữ 18-60 tuổi là cân thiết, trong đó, chú ý các phụ nữ sinh sống vùng nông thôn, học vấn thấp, hạn chế tiếp cận thông tin liên quan UTV.

Tư khóa: phòng và phát hiện sớm ung thư vú, yếu tố liên quan.

\section{SUMMARY \\ ASSOCIATIED FACTORS TO KNOWLEDGE, PRACTICE OF PREVENTION AND EARLY DETECTION BREAST CANCER IN WOMEN 18-60 YEARS AT CAN THO CITY IN 2020}

Background: In order to strengthen knowledge, practice of prevention and early detection of breast cancer for women 18-60 years, finding out associated factors of them is important to determine intervention contents. Objectives: To identify some associated factors to good knowledge, practice for prevention

${ }^{1}$ Trường Đại học Y dược Cần Tho,

${ }^{2}$ Bênh viện Phu sản thành phố Cần Thơ

Chịu trách nhiệm chính: Nguyễn Minh Phương

Email: nmphuong@ctump.edu.vn

Ngày nhận bài: 4.01.2021

Ngày phản biên khoa học: 25.2.2021

Ngày duyệt bài: 10.3.2021

\section{Nguyễn Minh Phương ${ }^{1}$, Lê Thị Kim Định²}

and early detection of breast cancer among women 18-60 years in Can Tho city. Methods: A crosssectional study was conducted on 286 women 18-60 years in Can Tho city from May to September 2020. Logistic regression analysis was a method to define factors that really related to knowledge, practice of prevention and early detection of breast cancer. SPSS 20.0 software was used to analyze data. Results: There were three associated factors to knowledge, of which, knowledge among women living in urban areas, over secondary education and getting breast cancer information were better than rural areas 1,944 times (CI 95\% 1,015-3,722), secondary school or lower 2,856 times (CI 95\% 1,169-6,979) and without breast cancer information 3.264 times (CI 95\% 1,728$6,163)$ with $p<0,05$. Family history of breast cancer, getting breast cancer information and good knowledge of breast cancer screening and early detection were defined three associated factors to practice of prevention and early detection of breast cancer for women $18-60$ years. The difference was statistically significant with $\mathrm{p}<0,05$ and OR respectively 4,106 (CI $95 \% 1,404-12,01$ ); 2,763 (CI 95\% 1,298-5,882) and 2,089 (CI 95\% 1,01-4,32). Conclusions: Intervention of associated factors to knowledge, practice of prevention and early detection of breast cancer among women $18-60$ years is necessary, in which, to pay attention rural areas, low education, without breast cancer information.

Keywords: breast cancer prevention and early detection, associated factors.

\section{I. ĐẶT VẤN ĐỀ}

Ung thư vú là loại ung thư phổ biến nhất ở phụ nữ cả ở các nước phát triển và các nước đang phát triển. Theo thống kê của Tổ chức $Y$ tế Thế giới (WHO), ước tính năm 2018 trên toàn thế giới có khoảng 2,1 triệu ca mới mắc ung thư vú, chiếm $11,6 \%$ trong các loại ung thư [9]. Tại Viết nam, ước tính năm 2020, số ca mắc UTV là $38,1 / 100.000$, đây thực sự là môt gánh nặng cho bản thân người bệnh, gia đình bệnh nhân và toàn xã hội [9]. Việc tầm soát và phát hiện càng sớm UTV sẽ giúp điêu trị bệnh càng đởn giản, hiệu quả điều trị càng cao, chi phí điều trị càng thấp [6]. Nhiều nghiên cứu thử nghiệm lâm sàng ngày nay đã khẳng định hiệu quả của việc sàng loc phát hiện sớm đối với phu nữ từ 40 tuổi trở lển sẽ giúp giảm tỷ lệ tử vong do bệnh UTV trong khoảng 25-30\%. Các phương pháp thường sử dụng bao gồm: tự khám vú; khám vú lâm sàng và chụp X-quang tuyến vú $[1],[6]$. 
Môt số nghiên cứu trên thế giới và Viêt Nam cho thấy kiến thức, thực hành phòng chống UTV ở phụ nữ chưa cao. Deniz S, Kurt B [7] ghi nhận tỷ lệ kiến thức và thực hành tốt về sàng lọc UTV dao động từ 25-27\%; Đào Trung Nguyên, Đỗ Thị Lệ Hằng [4] cho thấy tỷ lệ này dao động từ $11-19 \%$. Như vậy, việc tăng cường kiến thức, thực hành phòng và và phát hiên sớm UTV ở phư nữ có giá trị và ý nghĩa thực tiễn tại cộng đồng. Hiệu quả của can thiệp truyền thông trong tăng kiến thức, thực hành về phòng và phát hiện sớm UTV đã được chứng minh cũng như kiến nghị ở nhiều nghiên cứu như Yoshany N (2016) Nguyễn Hữu Châu (2015)[1], Phạm Cẩm Phương (2016-2017)[5]. Nhằm hổ trợ nhà quản lý y tế có cơ sở khoa học lựa chọn đối tượng, yếu tố ưu tiên can thiệp phòng và phát hiện sớm UTV, giúp công tác can thiệp truyền thông đạt hiệu quả, mục tiêu nghiên cứu là "Xác định một số yếu tố liển quan đến kiến thức, thực hành đúng về phòng và phát hiện sớm ung thư vú ở phu nữ 18-60 tuối tại thành phố Cần Tho".

\section{II. ĐỐI TƯợNG VÀ PHƯƠNG PHÁP NGHIÊN CỨU}

2.1. Đối tượng nghiên cứu. Phụ nữ 18-60 tuổi cư trú tại thành phố Cần Thơ từ tháng 5 đến tháng 9 năm 2020

Tiêu chuẩn chọn vào: Phụ nữ 18-60 tuổi có hộ khẩu thường trú tại thành số Cần Thơ (từ 6 tháng trở lên) trong thời gian nghiên cứu và đồng ý tham gia nghiên cứu.

Tiêu chuẩn loại trừ: Người mắc bệnh lý về tâm thần, thiểu năng trí tuệ. Đã chẩn đoán bệnh UTV. Đã được cán bộ y tể hướng dẫn sàng lọc UTV trước thời điểm nghiên cứu.

\subsection{Phương pháp nghiên cứu}

Thiết kế nghiên cứu: Nghiên cứu mô tả cắt ngang.

Cõ̃ mẫu :

$$
n=\frac{z_{1-\alpha / 2}^{2} \cdot p(1-p)}{d^{2}}
$$

- Z: hệ số tin cậy. Với độ tin cậy $95 \%$ thì Z = 1,96. d: sai số cho phép, chọn $d=0,05$

- p: Ước lượng tỷ lệ kiến thức, thực hành tốt của phụ nữ trong phòng và phát hiện sớm UTV. Theo Nguyễn Thị Quế Lâm, tỷ lệ kiến thức tốt là $21,2 \%$; Bùi Thị Duyên, tỷ lệ thực hành tốt là $22,3 \%$ [2], [3].

Thay vào công thức, chọn cõ̃ mẫu lớn nhất $\mathrm{n}$ $=267$. Cộng $5 \%$ dự phòng mẫu, cõ mẫu nghiên cứu $\mathrm{n}=281$; thực tế nghiên cứu trên $\mathrm{n}=286$.

Phương pháp chọn mấu: Chọn mẫu theo phương pháp phân tầng

Nội dung nghiên cứu: Yếu tố liên quan đến kiến thức, thực hành về phòng và phát hiện sớm ung thư vú gồm đặc điểm dân số (tuổi, nơi cư trú, kinh tế, nghề nghiệp, học vấn, tình trạng hôn nhân, số con), tìm hiểu thông tin về ung thư vú, tiền sử mắc bệnh ung thư vú. Nội dung kiến thức gồm 3 nội dung chính là kiến thức về bệnh ung thư vú, các biện pháp phòng ngừa bệnh ung thư vú, kiến thức về phát hiện sớm ung thư vú. Thực hành đánh giá trên 2 nội dung là phòng bệnh ung thư vú và phát hiện sớm ung thư vú. Kiến thức và thực hành tốt: đạt $\geq 75 \%$ nội dung khảo sát.

Xử lý và phân tích số liệu: phần mền SPSS 20.0. Xử lý yếu tố liên quan đến kiến thức, thực hành bằng phương pháp hồi qui logistic đa biến, sự khác biệt có ý nghĩa với $p<0,05$.

\section{KẾT QUẢ NGHIÊN CỨU}

\section{1. Đặc điểm của đối tượng}

Bảng 1. Đặc điểm về tuối, địa dư, dân tộc, kinh tế của đối tượng

\begin{tabular}{|c|c|c|c|}
\hline \multicolumn{2}{|c|}{ Đặc điểm chung } & Tân số & Tỷ lệ \% \\
\hline \multirow{4}{*}{$\begin{array}{c}\text { Nhóm } \\
\text { tuổi }\end{array}$} & $18-24$ & 64 & 22,4 \\
\cline { 2 - 4 } & $25-29$ & 31 & 10,8 \\
\cline { 2 - 4 } & $30-39$ & 65 & 22,7 \\
\cline { 2 - 4 } & $40-49$ & 58 & 20,3 \\
\cline { 2 - 4 } & $50-60$ & 68 & 23,8 \\
\cline { 2 - 4 } & Trung bình & \multicolumn{2}{|c|}{$37,9 \pm 12,9$} \\
\hline Nơi cư & Thành thị & 163 & 57,0 \\
\cline { 2 - 4 } trú & Nông thôn & 123 & 43,0 \\
\hline Dân & Kinh & 267 & 93,4 \\
\cline { 2 - 4 } tộc & Khác & 19 & 6,6 \\
\hline \multirow{2}{*}{ Kinh tế } & Nghèo, cận nghèo & 17 & 5,9 \\
\cline { 2 - 4 } & Không nghèo & 269 & 94,1 \\
\hline
\end{tabular}

Tuối trung bình là $37,9 \pm 12,9$; phân bố tương đối đều ở các nhóm tuổi từ 20-23\% ở nhóm 18-24; 30-39; 40-49 và 50-60 tuổi; nhóm thấp nhất là 25-29 tuổi với $10,8 \%$. Thành thị chiếm 57\%; dân tộc Kinh chiếm 93,4\%; 5,9\% kinh tế nghèo, cận nghèo.

Bảng 2. Hồn nhân, số con, tiền sử gia đình mắc UTV và tìm hiểu thông tin về UTV

\begin{tabular}{|c|c|c|c|}
\hline \multicolumn{2}{|c|}{ Đặc điểm chung } & Tân số & Tỷ lệ $\%$ \\
\hline Tình trạng hôn & Độc thân & 84 & 29,4 \\
\cline { 2 - 4 } nhân & Khác & 202 & 70,6 \\
\hline \multirow{2}{*}{ Số con } & $<2$ con & 149 & 52,1 \\
\cline { 2 - 4 } & $\geq 2$ con & 137 & 47,9 \\
\hline Tiền sử gia đình & Có & 17 & 5,9 \\
\cline { 2 - 4 } mắc UTV & Không & 269 & 94,1 \\
\hline Tìm hiếu thông tin & Có & 114 & 39,9 \\
\cline { 2 - 4 } về ung thư vú & Không & 172 & 60,1 \\
\hline
\end{tabular}

Tỷ lệ độc thân chiếm 29,4\%; 52,1\% có dưới 2 con; $5,9 \%$ gia đình có tiền sử mắc bệnh ung thư vú; $39,9 \%$ đối tượng có tìm hiểu thông tin về bệnh ung thư vú. 
Bảng 3. Đặc điểm về kiên thức, thực hành về phòng và phát hiện sớm ung thư vú

\begin{tabular}{|c|c|c|}
\hline $\begin{array}{c}\text { Kiến thức, } \\
\text { thực hành }\end{array}$ & Tốt & Chưa tốt \\
\hline Kiến thức & $93(32,5 \%)$ & $193(67,5 \%)$ \\
\hline
\end{tabular}

\begin{tabular}{l|l|l|} 
Thực hành & $57(19,9 \%)$ & $229(80,1 \%)$ \\
\hline
\end{tabular}

Tỷ lệ kiến thức, thực hành tốt về phòng và phát hiển sớm ung thư vú ở phụ nữ 18-60 tuổi chiếm $32,5 \%$ và $19,9 \%$.

3.2. Yếu tố liên quan kiến thức, thực hành về phòng và phát hiện sớm ung thư vú Bảng 4. Phân tích yếu tố liên quan giữa kiến thức và một số yểu tố

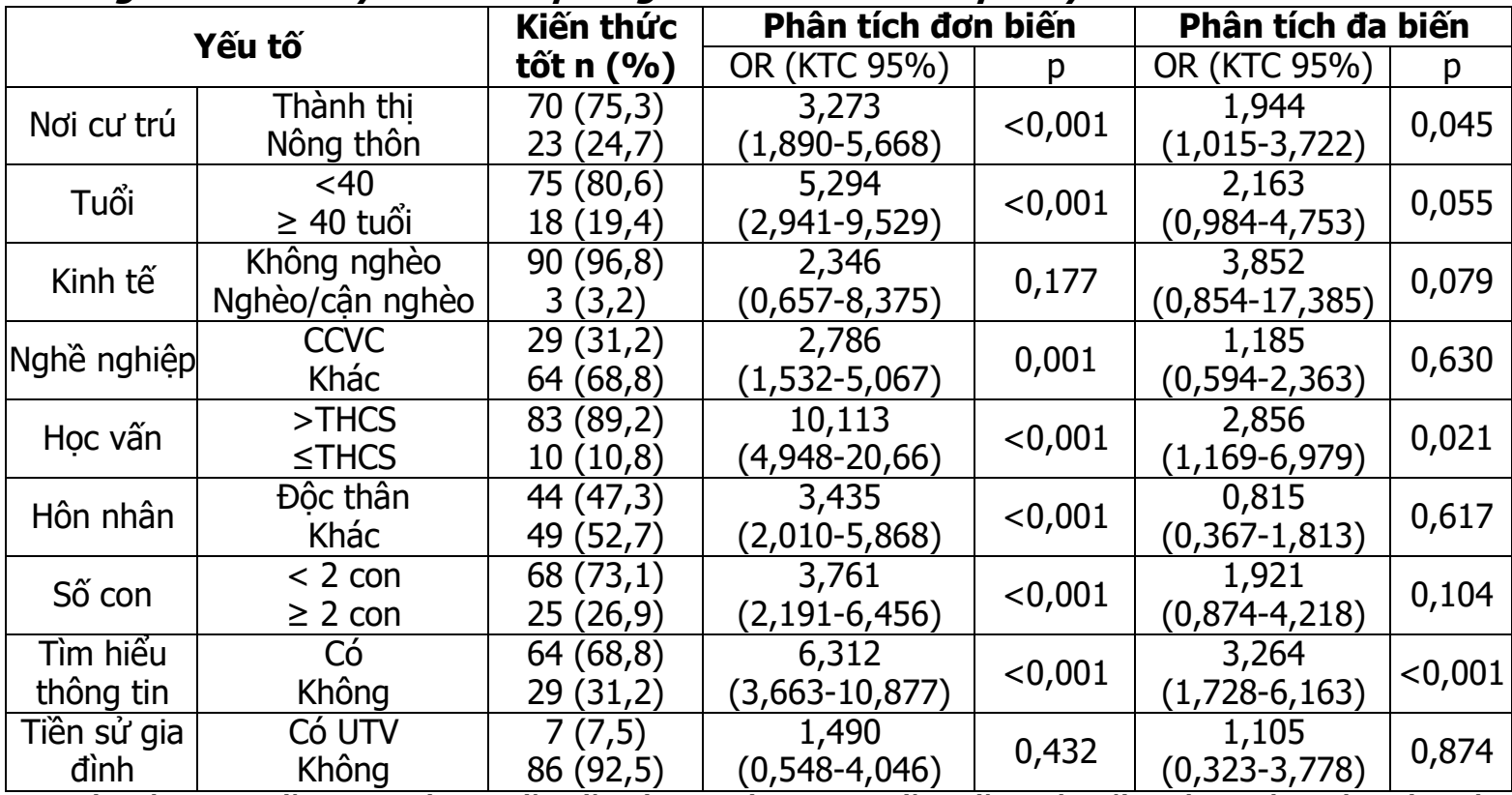

Phân tích đa biến ghi nhân 3 yếu tố thật sự liên quan đến kiến thức về phòng và phát hiện sớm UTV là sống thành thị, học vấn $>$ THCS và có tìm hiểu thông tin về UTV với $p<0,05$.

Bảng 5. Phân tích đa biến liên quan giữa thực hành và một số yêu tố

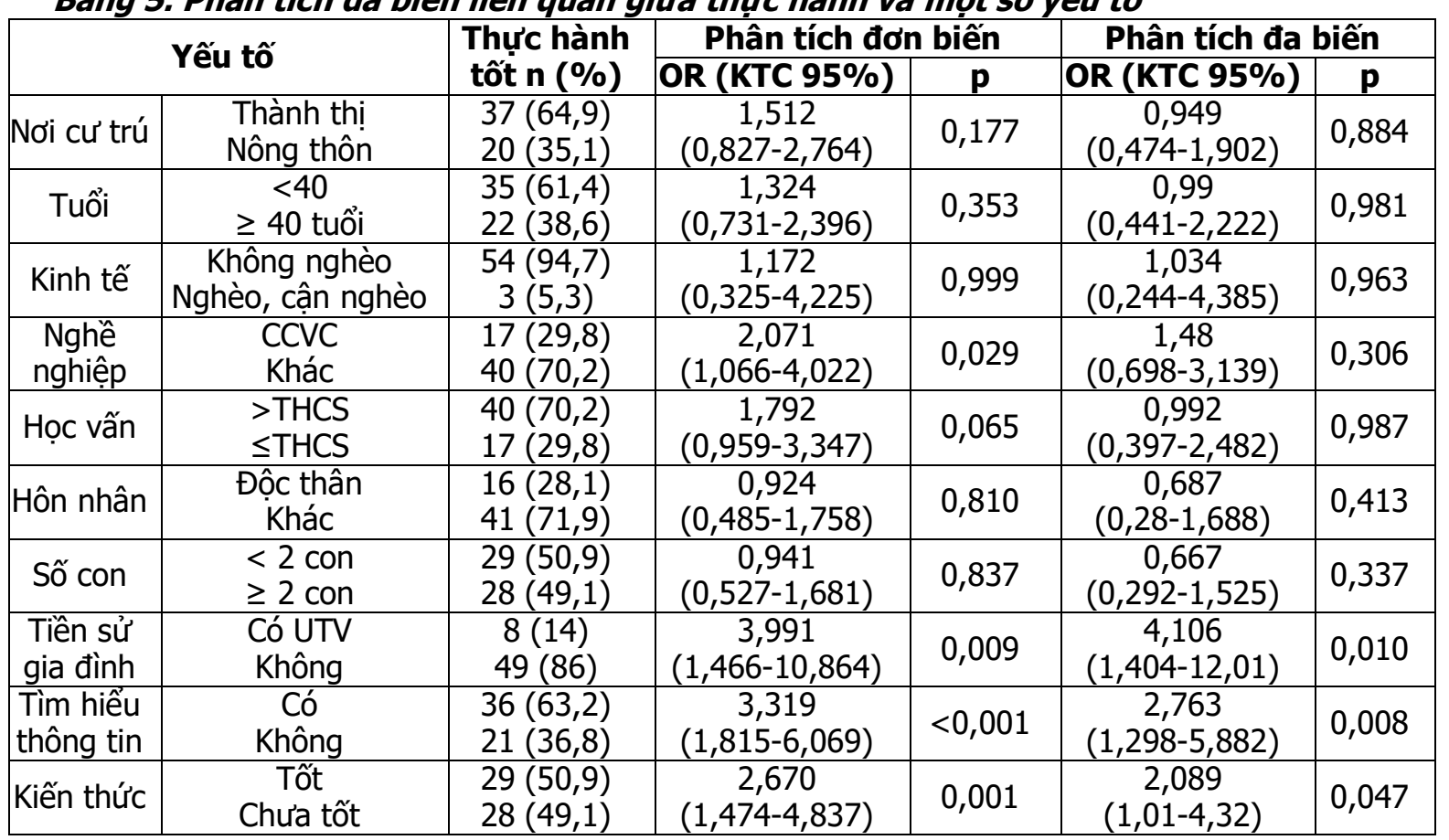


Phân tích đa biến ghi nhân 3 yếu tố thật sự liên quan đến thực hành chung về phòng và phát hiện sớm UTV là tiền sử gia đình có UTV, có tìm hiếu thông tin về UTV và kiến thức chung đúng lần lượt 4,106; 2,763 và 2,089 với $p<0,05$.

\section{BÀN LUẬN}

4.1. Đặc điểm chung. Tuổi trung bình của đối tượng là $37,9 \pm 12,9$; phân bố tương đối đều ở các nhóm tuổi từ 20-23\% ở nhóm 18-24; 3039; 40-49 và $50-60$ tuổi; nhóm thấp nhất là 2529 tuổi với 10,8\%. Chủ yếu đối tượng nghiên cứu tập trung >40 tuổi. Đây là độ tuổi có nguy cơ mẳc UTV tăng cao, do vậy việc nâng nhận thức cho phụ nữ có thể sẽ đem lại tác động tích cực đến việc phòng và phát hiện sớm bệnh, góp phần tăng hiệu quả điều trị. Tuổi thấp hớn so với nghiên cứu của Deniz và cộng sư thực hiên với đối tượng nghiên cứu có độ tuổi trung bình là $45,6 \pm 11,4$, với nhóm <45 tuổi chiếm $51,3 \%$ [7]. Đa số đối tượng ở nghiên cứu của chúng tôi sinh sống ở thành thị chiếm $57 \%$; dân tộc Kinh chiếm 93,4\%. Tỷ lệ độc thân chiếm 29,4\%; $52,1 \%$ có dưới 2 con; $5,9 \%$ gia đình có tiền sử mắc bệnh ung thư vú; $39,9 \%$ đối tượng có tìm hiểu thông tin về bênh ung thư vú. Nhìn chung, đặc điểm chung đối tượng nghiên cứu khá phù hợp với nhóm tuổi 16-60 tuổi và trên nhóm đối tượng là phụ nữ.

Nghiên cứu đánh giá về thực trang kiến thức, thực hành về phòng và phát hiện sớm ung thư vú. Nội dung đánh giá khá đầy đủ. Về kiến thức, ghi nhận sự hiểu biết của đối tượng về bệnh ung thư vú (yếu tố làm tăng nguy cớ UTV, kiến thức về phòng bệnh, kiến thức về sàng lọc UTV là tự khám vú, kiến thức về phát hiện UTV qua khám chuyên khoa, chụp Xquang tuyến vú. Về thực hành, khảo sát đầy đủ các hành vi phòng UTV, thực hiện tự khám vú, khám chuyên khoa, chụp Xquang tuyến vú. Kết quả ghi nhận $32,5 \%$ phụ nữ 18-60 tuổi có kiến thức tốt, $19,9 \%$ có thực hành tốt. Nhìn chung, kết quả nghiên cứu cho thấy kiến thức, thực hành về phòng và phát hiện sớm ung thư vú ở phụ nữ 18-60 tuổi chưa cao. Như vậy, rất cần thiết để những chương trình truyền thông giáo dục sức khỏe về ung thư vú tại cộng đồng để nâng cao nhận thức của những phụ nữ độ tuổi 18-60 tuổi đối với việc phòng và phát hiện sớm bênh UTV.

4.2. Môt số yếu tố liên quan đến kiến thức, thực hành về phòng và phát hiện sớm ung thư vú. Kết quả phân tích đơn biến về yếu tố liên quan kiến thức phòng và phát hiện sớm ung thư vú cho thấy có 7 yếu tố liên quan đễn kiến thức, trong đó, tỷ lệ đối tượng có kiến thức tốt về các nội dung này thuộc nhóm phụ nữ cư trú tại thành thị, tuổi <40, nghề nghiệp là công chức viên chức, học vấn > THCS, sống độc thân, có dưới 2 con và chủ động tìm hiểu thông tin về UTV $(p<0,05)$. Phân tích đa biến, kết quả ghi nhận còn 3 yếu tố thật sự liên quan đến kiến thức về phòng và phát hiện sớm UTV là nơi cư trú, trình độ và tìm hiểu thông tin về UTV. Cụ thể, sống thành thị, học vấn >THCS và có tìm hiểu thông tin về UTV lần lượt $1,944(1,015-$ $3,722) ; 2,856(1,169-6,979)$ và $3,264(1,728$ $6,163)$ với $p<0,05$. Tương tự nghiên cứu của tác giả Nguyễn Hữu Châu đã chỉ ra rằng phụ nữ có trình độ học vấn từ THPT trở lên có kiến thức đúng về bệnh UTV cao hơn những phụ nữ có trình độ học vấn dưới THPT[1].

Đối với thực hành, phân tích đơn biến ghi nhận 4 yếu tố liên quan gồm nghề nghiệp, tiền sử gia đình có người UTV, tìm hiểu thông tin về UTV, kiến thức của đối tượng với $p<0,05$. Sau phân tích đa biến, kết quả ghi nhận 3 yếu tố thật sự liên quan đến thực hành về phòng và phát hiện sớm UTV. Trong đó, thực hành tốt cao hơn ở nhóm đối tương là tiền sử gia đình có UTV, chủ động tìm hiểu thông tin về UTV và kiến thức tốt lần lượt $4,106(1,404-12,01) ; 2,763(1,298-$ $5,882)$ và $2,089(1,01-4,32)$ với $p<0,05$. Kết quả nghiên cứu của chúng tôi cho thây việc tìm hiểu tiếp nhận các thông tin về phòng và phát hiện sớm UTV có ảnh hưởng tới kiến thức, thực hành về phòng bênh UTV của đối tương nghiên cứu. Điều này cũng phù hợp thực tể là người được tiếp cận với những nguồn thông tin thì sẽ có hiểu biết, nhận thức về bệnh tật hơn so với những người không tiếp cận nguồn thông tin, từ đó sẽ có nhân thức phù hợp tác động vào những việc làm giảm những yếu tố nguy cơ gây mắc UTV. Tương tự các nghiên cứu khác như Đào Trung Nguyên [4] năm 2017 về kiến thức và thực hành phát hiện sớm ung thư vú cho thấy nhận được nguồn thông tin về UTV có kiến thức đúng về bệnh UTV cao hơn gấp gần 6 lần so với nhóm chưa từng được nghe vê UTV $(p<0,001)$; Nguyễn Hữu Châu (2015) cho thấy phụ nữ đã nghe thông tin về UTV có kiến thức đúng về bệnh UTV cao hơn gấp 3 lần so với phụ nữ chưa từng được nghe về UTV; Bùi Thị Duyên cho thây nhóm đối tượng được nghe/xem/đọc thông tin về phát hiện sớm ung thư vú, được tiếp cận chương trình khám phát hiện sớm ung thư vú thì có thực hành tốt hơn nhóm còn lại [2].

Mối liên quan giữa kiến thức và thực hành về sàng lọc và phát hiện UTV cũng được ghi nhận ở 
các nghiên cứu khác. Đào Trung Nguyên [5] cho thấy đối tượng có kiến thức đạt về các phương pháp tự khám vú thì có tỷ lệ thực hành các phương pháp phát hiện sớm UTV cao hơn so với nhóm không nhận được nguồn thông tin về UTV, có kiến thức không đạt. Rõ ràng, có nhận được nguồn thông tin và có kiến thức đạt sẽ giúp họ biết được cách thực hành như thế nào là đúng, khám với tần suất như thế nào là phù hợp cũng như thời điểm, thời gian định kỳ cần đi khám, sàng lọc phát hiện sớm những bất thường sớm để có thể điều trị kịp thời. Kết quả này cũng tương đồng với nghiên cứu của Tam Trương Donnelly cho rằng có nhận thức cao hơn dẫn đến thực hành phát hiên sớm UTV tốt hơn ở những phụ nữ được nghiên cứu tại Ả rập [8]. Hay nghiên cứu của tác giả Bùi Thị Thảo tại Hà Nội cho thấy nhóm có kiến thức chưa đạt về tự khám vú thì có điểm thực hành chưa đạt cao gấp 4,3 lần nhóm có kiến thức đạt. Qua đó chúng ta có thể thấy, vai trò quan trọng của việc cung cấp nguồn thông tin về phòng và phát hiện sớm UTV. Để có thể tăng tỷ lệ thực hành phòng và phát hiện sớm UTV ở phụ nữ thì cần phải tăng tỷ lệ có kiến thức đạt qua các hoạt động, chương trình tuyên truyền, hướng dẫn và cung cấp thông tin.

\section{KẾT LUÂ̂N}

Yễu tố liên quan kiến thức về phòng và phát hiện sớm UTV ở phụ nữ 18-60 tuổi: sống thành thị, học vấn > THCS và có tìm hiểu thông tin về UTV có kiến thức tốt hơn nhóm còn lại lần lượt $1,944(1,015-3,722) ; 2,856 \quad(1,169-6,979)$ và $3,264(1,728-6,163)$ với $p<0,05$. Về thực hành, thực hành tốt cao hơn ở nhóm tiền sử gia đình có UTV, chủ động tìm hiểu thông tin về UTV và kiến thức tốt lần lượt 4,106 (1,404-12,01); 2,763 $(1,298-5,882)$ và $2,089(1,01-4,32)$ với $p<0,05$.

\section{TÀI LIÊU THAM KHẢO}

1. Nguyễn Hữu Châu (2015), "Nghiên cứu thực trạng kiến thức, thái độ, thực hành về bệnh ung thư vú ở phụ nữ 20 - 60 tuổi trên đia bàn tỉnh Khánh Hòa", Tạp chí Ung thư học Việt Nam, số 5/2015, tr.22-25.

2. Bùi Thị Duyên (2018). Kiến thức, thái độ và thưc hành phát hiên sớm ung thư vú và một số yếu tố liên quan của phụ nữ tữ 20 - 49 tuổi tại xã Cẩm Giang, Huyện Cẩm Thủy, Thanh Hóa, Luận văn thăc sỹ Y tế công cộng, Trường Đại hợ Y Y HN.

3. Nguyễn Thị Quế Lâm (2017), Tìm hiểu một số yêu tố liên quan đến kiến thức, thái độ và thực hành về phòng chống bệnh ung thư vú ở phụ nữ thị xã Ninh Hòa, tỉnh K̉hánh Hòa, Đề tài cơ sở Trung tâm Truyền thông GDSK Khánh Hòa

4. Đào Trung Nguyên (2017), Kiến thức, thực hành về phòng và phát hiện sớm ung thư vú của phư nữ ở công ty cổ phần may 10 và một số yếu tố liên quan, Luận văn tốt nghiệp trường địa học $Y$ Hà Nội.

5. Phạm Cẩm Phương (2017), "Đánh giá kết quả tư vấn khám sàng lọc và phát hiên sớm ung thư vú ở nữ giới tại thành phô Hà Nội và các tỉnh lân cận", Tạp chí y học Việt Nam, Tập 1, tr. 41-45.

6. Đố Quốc Tiệp, Mái Xuân Sự, Phan Tiến Hoàng và cô̂ng sứ (2015). Nghiên cứu kiến thức cửa người dân về phòng chống bệnh ung thư tại Quảng Bình. Tạp chí Ung thư học Việt Nam, số 5/2015, tr.41-44.

7. Deniz S, Kurt B, Oğuzöncül AF, Nazlıcan E, Akbaba M, Nayir T (2017). Knowledge, attitudes and behaviours of women regarding breast and cervical cancer in Malatya, Turkey. Plos One, Vol 12 (11), pp.1-9.

8. Donnelly TT, Khater AH, Al-Bader SB, Al Kuwari MG, Malik M, Al-Meer N, Singh R, Fung $T$ (2014). Factors that influence awareness of breast cancer screening among Arab women in Qatar: results from a cross sectional survey. Asian Pac J Cancer Prev, Vol 15 (23), pp.10157-10164.

9. WHO (2018). New Global Cancer Data: GLOBOCAN 2018.

\section{ĐÁNH GIÁ KẾT QUẢ ĐÎ̀̂U TRI VẾT LOÉT LÂU LIỀN CHI DƯớI Ở NGƯỜI LỚN TUỔI}

\section{TÓM TẮT}

Mục tiêu: Đánh giá kết quả điều trị vết loét lâu liền chi dưới ở người lớn bằng tại Bệnh viện Thống

*Bênh viện Thống Nhất, TP Hồ Chí Minh

Chịu trách nhiệm chính: Võ Thành Toàn

Email: vothanhtoan1990@yahoo.com

Ngày nhận bài: 5.01.2021

Ngày phản biện khoa học: 25.2.2021

Ngày duyệt bài: 9.3.2021

\section{Võ Thành Toàn*, Nguyễn Bảo Lục*}

Nhất. Đối tượng và phương pháp: 40 bệnh nhân độ tuổi từ 60 trở lên, có các vết loét lâu liền chi dưới do nhiều nguyên nhân được điều trị tại khoa Chấn thương Chỉnh hình, bệnh viện Thống Nhất từ 1/2018 đến 1/2019. Kết quả: Có 20 ca ghép da với tỉ lệ sống 75 - 100\%; 4 ca được chuyển vạt hiển che phư với 3 vạt sống hoàn toàn; 8 ca chuyển vạt da cân cẳng chân cuống ngoại vi sống hoàn toàn. Chuyển vạt cân mõ với 4 ca vết thương chậm liền. Ngoài ra có 4 ca chuyển vạt cơ sinh đôi thành công. Kêt luận: Vết loét chi dưới có nguyên nhân đa dạng hay gặp nhất là ở 